\title{
Measurement of Lipolysis
}

\author{
Martina Schweiger ${ }^{1}$, Thomas O. Eichmann, Ulrike Taschler, Robert Zimmermann, Rudolf \\ Zechner, and Achim Lass ${ }^{1}$ \\ Institute of Molecular Biosciences, University of Graz, Graz, Austria
}

\begin{abstract}
Lipolysis is defined as the hydrolytic cleavage of ester bonds in triglycerides (TGs), resulting in the generation of fatty acids (FAs) and glycerol. The two major TG pools in the body of vertebrates comprise intracellular TGs and plasma/nutritional TGs. Accordingly, this leads to the discrimination between intracellular and intravascular/gastrointestinal lipolysis, respectively. This chapter focuses exclusively on intracellular lipolysis, referred to as lipolysis herein. The lipolytic cleavage of TGs occurs in essentially all cells and tissues of the body. In all of them, the resulting FAs are utilized endogenously for energy production or biosynthetic pathways with one exception, white adipose tissue (WAT). WAT releases FAs and glycerol to supply nonadipose tissues at times of nutrient deprivation. The fundamental role of lipolysis in lipid and energy homeostasis requires the accurate measurement of lipase activities and lipolytic rates. The recent discovery of new enzymes and regulators that mediate the hydrolysis of TG has made these measurements more complex. Here, we describe detailed methodology for how to measure lipolysis and specific enzymes' activities in cells, organs, and their respective extracts.
\end{abstract}

\section{INTRODUCTION}

In times of abundant nutrients, virtually all eukaryotic organisms are able to store excess energy in form of triglycerides (TGs) that can be reutilized in times of nutrient deprivation or high-energy demand. In all cell types, TGs are stored in lipid droplets (LDs) composed of variable amounts of neutral lipids, phospholipids, and LD-associated proteins. Vertebrates, in particular, have developed white adipose tissue (WAT) as a highly specialized tissue for the deposition and remobilization of TG. In WAT, a tight balance between lipolysis and lipogenesis controls homeostasis and body composition. Dysregulation of this balance leads to either obesity or lipodystrophy. In nonadipose tissues, TG storage is normally much more short term with a small number of LDs and a high LD turnover. Nevertheless, lipolysis is also essential in nonadipose tissues for instant provision of fatty acids (FAs) upon demand, particularly in highly oxidative tissues such as the brown adipose tissue, liver, cardiac and skeletal muscles, or macrophages. In these tissues, FAs not only are efficient energy substrates but also represent basic building blocks for the synthesis of membrane lipids or intracellular signaling molecules. In addition, FAs have also been recognized as signaling molecules per se, which can bind to and thereby activate members of the nuclear receptor

(C) 2014 Elsevier Inc. All rights reserved.

${ }^{1}$ Corresponding authors: tina.schweiger@uni-graz.at; achim.lass@uni-graz.at. 
family of transcription factors (Kliewer et al., 1997). Defective lipolysis in nonadipose tissues impairs their normal function, leading to excessive TG accumulation and neutral lipid storage disease. Conversely, overabundance of FAs due to unrestrained lipolysis results in lipotoxicity, which is characterized by ER stress, mitochondrial dysfunction, and cell death. Elevated cellular FA concentrations, independent of whether they originate from exogenous lipolysis in WAT or endogenous lipolysis in nonadipose tissues, cause prevalent metabolic disorders such as insulin resistance, type II diabetes, liver steatosis, or atherosclerosis. Additionally, dysregulated lipolysis is also observed in other pathological conditions such as in cancer-induced cachexia.

\subsection{Current model of lipolysis}

Lipolysis requires specific enzymes commonly called lipases for each step of ester bond hydrolysis in TGs. To date, three major lipases have been identified: (i) Adipose triglyceride lipase (ATGL) performs the first step of TG hydrolysis, generating diglycerides (DGs) and FAs (Zimmermann et al., 2004). Its activity is tightly regulated by two accessory proteins: comparative gene identification-58 (CGI-58) coactivates the hydrolase activity of ATGL and G0/G1 switch gene 2 (G0S2) inactivates the hydrolase activity of ATGL (Lass et al., 2006; Yamaguchi, 2010; Yamaguchi \& Osumi, 2009; Yang et al., 2010). (ii) Hormonesensitive lipase (HSL) performs the second step and hydrolyzes DGs, generating monoglycerides (MGs) and FAs. In contrast to ATGL, HSL exhibits a broader substrate specificity, also hydrolyzing TGs, cholesteryl esters, MGs, and retinyl esters in addition to DGs. (iii) Monoglyceride lipase (MGL) is selective for MGs and generates glycerol and the third FA (Vaughan, Berger, \& Steinberg, 1964). Thus, lipolysis constitutes a coordinated three-step process catalyzed by three different enzymes, which degrade TG into glycerol and FAs (Fig. 10.1). The relative importance of these three enzymes, however, highly depends on their tissue-specific expression pattern and the metabolic state. In WAT, ATGL, HSL, and MGL are responsible for more than $90 \%$ of its lipolytic activity (Schweiger et al., 2006). This may be different in other tissues such as skeletal muscle or cardiac muscle, where other, possibly unknown enzymes may also contribute to intracellular TG hydrolase activity (Haemmerle et al., 2006).

\subsection{Regulation of adipose tissue lipolysis}

As mentioned earlier, WAT provides FAs to tissues with high-energy demand at times of fasting. This necessitates that FAs and glycerol derived from WAT lipolysis enter the bloodstream, which makes WAT lipolysis the main determinant of plasma FA concentrations. Numerous physiological conditions, hormones, and cytokines regulate WAT lipolysis on multiple levels. The most important regulatory steps to control enzyme activity include (i) regulation of lipase gene expression, (ii) translation and stability of lipases and accessory proteins, (iii) control of intracellular localization of lipases, (iv) posttranslational modifications (e.g., phosphorylation), and (v) regulation of lipase activity via coregulators (e.g., CGI-58, G0S2, and perilipins).

Regulation of each of these steps is tissue-specific and often varies among different organisms. For example, while mRNA expression of ATGL is upregulated in response to fasting in murine WAT (reviewed in Zechner, Kienesberger, Haemmerle, Zimmermann, \& 
Lass, 2009), it is reduced in human WAT. Nevertheless, this reduction of ATGL mRNA in fasted human WAT is associated with increased ATGL protein concentrations (Nielsen et al., 2011) and, presumably, increased lipase activity. Similarly, despite drastically elevated lipolysis, ATGL and HSL mRNA expression is unaltered upon endurance training (Huijsman et al., 2009) or even decreased by the lipolysis-inducing (lipolytic) hormones isoproterenol and TNF-a (Kralisch et al., 2005). This indicates that lipolysis is predominantly regulated at the posttranscriptional and posttranslational level (Fig. 10.2). Accordingly, measurements of lipase mRNA levels are inadequate markers for the estimation of actual lipase activities.

To date, most work related to regulatory mechanisms controlling lipolysis focused on WAT. Oxidative tissues share many of the lipases and accessory proteins with adipose tissue, specific differences exist regarding expression of hormone receptors, signaling pathways, and LD composition and structure. These differences require better characterization. In WAT, the most important mechanism regulating lipolysis involve the activation of ATGL by CGI-58 and the protein kinase A (PKA) - mediated phosphorylation of HSL and perilipin-1. In the nonstimulated/basal state, CGI-58 is bound to perilipin-1 and unavailable for ATGL binding/activation. At the same time, HSL resides in the cytosol. Upon hormonal (e.g., $\beta$-adrenergic) stimulation, PKA phosphorylates both HSL and perilipin-1 on multiple serines, which causes HSL translocation to the LD (Clifford, Londos, Kraemer, Vernon, \& Yeaman, 2000; Egan et al., 1992). Phosphorylated perilipin-1 also releases CGI-58, which is now available for ATGL binding and activation (Granneman et al., 2006). Following hormone stimulation, ATGL also translocates from the cytosol to the LD surface. However, the underlying mechanism is not clear (Bezaire et al., 2009; Yang et al., 2010) (Fig. 10.2). G0S2 efficiently inhibits ATGL activity in in vitro lipase assays. Moreover, G0S2-deficient mice exhibit increased adipose tissue lipolysis, improved insulin sensitivity, and are resistant to diet induced liver steatosis (Zhang et al., 2013). Notably, G0S2 appears to be involved in the activation of lipolysis in adipocytes by TNF-a. Experiments in 3T3-L1 adipocytes showed that TNF-a decreases G0S2 mRNA and protein levels, leading to enhanced lipolysis (Yang, Zhang, Heckmann, Lu, \& Liu, 2011).

\subsection{Strategies to assess lipolysis}

\subsubsection{Non-activity-based methods}

1.3.1.1 Quantitation of cell and tissue mRNA levels of lipases and regulatory proteins: Due to the convenience and simplicity of the involved methodology, the lipolytic activities in cells or tissues are often estimated by quantification of mRNA levels of lipases and regulatory proteins. It is assumed that changes in mRNA levels will lead to respective changes in the protein concentrations, which will finally translate into changes in the lipolytic activity. This conclusion, as mentioned before, is mostly unwarranted. Accordingly, determination of mRNA levels is only meaningful when the transcription, mRNA processing, or mRNA degradation of lipolytic genes is in question.

\subsubsection{Quantitation of protein concentrations of lipases and regulatory proteins: To} date, a number of very specific antibodies for lipolytic enzymes and regulatory proteins are available for various species including murine and human proteins. These tools have 
substantially broadened the assessment of protein levels of lipases and regulatory proteins, determination of which is necessary if translation from RNA, protein stability, or protein degradation is in question. Since lipase activities are regulated at the posttranscriptional level, a direct correlation between protein expression levels and activities usually does not exist.

1.3.1.3 Quantitation of HSL and perilipin phosphorylation state: The phosphorylation state of perilipin-1 and HSL is a good measure to investigate hormone-stimulated lipolysis. More precisely, the phosphorylation of HSL and perilipin is a direct readout for PKA activity, since these proteins are known substrates for PKA. Thus, this method is well suited when PKA activity has to be determined. However, PKA-mediated phosphorylation of HSL and perilipin does not necessarily correlate with lipolytic activities, since lipolysis is a complex orchestration between different lipolytic enzymes and regulatory proteins.

\subsubsection{Activity-based methods}

1.3.2.1 In vitro TG hydrolase activity: To directly measure lipolytic activities of tissues or cells, the in vitro TG hydrolase activity assay is widely used. This assay is relatively easy to perform and meaningful in that it provides a good measure for the lipolytic capacity in a given sample. It is based on an artificial, radioactive isotope-labeled triolein substrate where the lipolytic activity of the sample leads to a release of radiolabeled FAs. Hence, it is important that samples do not contain large amounts of endogenous TG, since these would also be hydrolyzed but as they are not labeled they would not be detected in the assay. Thus, endogenous TG lowers the rate of hydrolysis in the assay by diluting the artificial substrate. Usually, a 20,000 $\times g$ infranatant of tissue homogenates is used because LDs will float on top and can be easily removed. Yet, by removing the LDs from the sample, also, a portion of lipases and regulatory proteins is removed and lost for the measurement. As shown in Fig. 10.2, the majority of ATGL and HSL translocates from the cytosol to the LD surface upon $\beta$-adrenergic stimulation. Thus, under these conditions, the major lipolytic activity of the sample is not accessible for TG hydrolase activity measurement.

1.3.2.2 LD-associated activity: To circumvent the limitations of the in vitro TG hydrolase assay, an analysis of the LD-associated lipolytic capacity can be performed. For this, LDs have to be isolated and purified by differential centrifugation (density gradient). Then, these LDs are incubated for "self-digestion" and released FAs are determined by an enzymatic test, which is a direct readout for the lipolytic capacity. Generally, LDs can be isolated from either cultured cells or tissues. The advantage of using cultured cells for LD isolation is that they can be transfected with a gene of interest (i.e., an LD-associated protein), whose role in lipolysis can then be analyzed. Furthermore, the TG moiety of LDs of cultured cells can also be radiolabeled, which enhances sensitivity and accuracy of the assay. LDs, isolated from tissues of genetically modified animals, can be used as substrate to more precisely determine the effect of the genetic manipulation on lipolysis. Furthermore, during "self-digestion" of LDs, the exogenous addition of proteins of interest (either purified or in lysates) allows investigators to assess their respective effect on lipolysis in a much-closer-to-reality system since the substrate, the isolated LDs, is composed of a biological complex mixture of lipid species and already contains numerous proteins, depending on cell type or tissue. Although 
this method is convenient, isolation of LDs is time-consuming and inactivation or mislocalization of proteins may occur.

1.3.2.3 Lipolysis of cultured adipocytes and organ explants: The most direct assessment of lipolysis is the measurement of the lipolytic products released by adipocytes or fat explants. This method is based on the measurement of lipolytic products (FAs and glycerol), which are released into the incubation media. In this scenario, two lipolytic states can be differentiated, the so-called basal and $\beta$-adrenergic-stimulated states. It is important to add bovine serum albumin (BSA) as FA acceptor to the incubation media since the extracellular accumulation of free FAs will promote reuptake of FAs and reesterification of glycerolipids. Despite an excess of FA acceptor in the media, not all FAs and glycerols generated during lipolysis are released to the media but used for intracellular needs. Thereby, FAs are readily activated by acyl-CoA synthetases (ACS) to FA-CoA, which serve as precursors for MG, DG, TG, and phospholipid (PL) synthesis. Although to a lesser extent, glycerol can also be recycled by glycerol kinase, glycerolphosphate-acyltransferase, acylglycerolphosphateacyltransferase, and lipin to DGs (Fig. 10.3). Thus, the molar ratio between FA and glycerol released into the media is usually closer to $1: 1$ under basal/non-lipolytic-stimulated conditions and only reaches a ratio of 3:1 under lipolytic-stimulated conditions (i.e., by $\beta$ adrenergic stimulation) or by the inhibition of ACS (i.e., by triacsin C; Paar et al., 2012).

\section{METHODOLOGICAL DESCRIPTION OF ACTIVITY-BASED ASSAYS}

\subsection{Measurement of in vitro TG hydrolase activity}

\subsubsection{Validity of the in vitro TG hydrolase assay to determine ATGL activity-}

The measurement of TG hydrolase activity in adipose tissue was originally optimized for HSL (Holm, Olivecrona, \& Ottosson, 2001). It was suggested that HSL hydrolyzes TG and DG to form MG and FA. MGL then hydrolyzes MG. At that time, TG hydrolysis was found to be highest at neutral $\mathrm{pH}$, using a substrate of triolein emulsified with phospholipids. Not surprisingly, ATGL is also maximally active under the same conditions. In the presence of CGI-58, the optimal pH for ATGL-mediated TG hydrolysis is pH 7.0 (Fig. 10.4). An increase to $\mathrm{pH} 8.0$ or decrease to $\mathrm{pH} 6.0$ results in a loss of nearly half of the activity. Using triolein as substrate, the acylglycerol hydrolase activity present in adipose tissue lysates derives mostly (>90\%) from ATGL, HSL, and MGL. To differentiate between TG hydrolase activities mediated by ATGL or HSL, a specific inhibitor for HSL can be used (Schweiger et al., 2006). Inhibition of HSL activity in WAT reduces the acylglycerol activity by approximately $60 \%$, which is expected since DG accumulates, and DG has two out of three FAs still esterified to the glycerol backbone. The absence of ATGL activity reduces the acylglycerol hydrolase activity of WAT by approximately $80 \%$, and no intermediary degradation products accumulate (Haemmerle et al., 2006).

For the determination of TG hydrolase activity, triolein is widely used as substrate. Detergents are often used for the preparation of emulsions, including phospholipids (PC/PI), cholate, Triton X-100, and glycerol or a combination thereof. BSA (FA-free) has to be added as FA acceptor since the solubility of FAs is limited and accumulation of FAs will inhibit rate of hydrolysis. Figure 10.5 depicts the effect of different substrate preparations on rate of hydrolysis of HSL, ATGL, and ATGL coactivated by CGI-58. HSL exhibits highest 
activity when phospholipids (PC/PI) are used for substrate preparation. When the substrate is prepared using Triton X-100 (0.025\%) or glycerol (2\%), HSL loses approximately 50\% of the activity. In the presence of cholate $(20 \mathrm{mM})$, HSL activity is reduced by $\sim 80 \%$ (Fig. 10.5A). For ATGL (Fig. 10.5B), the highest activity was obtained with PC/PI- and Triton X-100-stabilized substrates. Preparation of substrates either with cholate or glycerol reduced activities to $35 \%$ and $8 \%$, respectively. This suggests that for measurement of ATGL activity, PC/PI and Triton X-100 are suitable. However, this is not the case for CGI-58coactivated ATGL activity. CGI-58 coactivation of ATGL is only seen using a PC/PIemulsified substrate (Fig. 10.5C), implicating that the interaction of ATGL and CGI-58 is highly affected by the nature of a detergent.

\subsubsection{Required materials}

- Solution A: $0.25 M$ sucrose, $1 \mathrm{~m} M$ EDTA, $1 \mathrm{~m} M$ DTT, pH 7.0, $1 \mu \mathrm{g} / \mathrm{ml}$ pepstatin, 2 $\mu \mathrm{g} / \mathrm{ml}$ antipain, and $20 \mu \mathrm{g} / \mathrm{ml}$ leupeptin as protease inhibitors (Pi's).

- Prepare $20 \mathrm{mg} / \mathrm{ml}(\sim 25 \mathrm{mM})$ phosphatidylcholine (PC) from egg yolk and phosphatidylinositol (PI) from soybean (Sigma-Aldrich, St Louis, MO, cat. no. P-3556 and cat. no. P-0639, respectively) with a ratio of 3:1 in chloroform and store at $-20{ }^{\circ} \mathrm{C}$.

- Prepare a $100 \mathrm{mg} / \mathrm{ml}(113 \mathrm{mM}$ ) solution of triolein (trioleoylglycerol, TO; SigmaAldrich, cat. no. T-7140) in toluene and store at $-20^{\circ} \mathrm{C}$.

- Prepare a $0.5 \mu \mathrm{Ci} / \mu \mathrm{l}$ solution of TO [9,10(N)-3H] (PerkinElmer, Waltham, MA, cat. no. NET431L005MC) in toluene and store in aliquots of $2 \mathrm{ml}$ at $-20{ }^{\circ} \mathrm{C}$.

- $\quad 0.1 M$ potassium $\times$ phosphate buffer (KPB; $\mathrm{pH} 7.0)$ is prepared freshly.

- Prepare a 20\% solution of BSA (FA-free; Sigma-Aldrich, cat. no. A6003) in $0.1 \mathrm{M}$ $\mathrm{KPB}(\mathrm{pH} 7.0)$ and store in aliquots at $-20^{\circ} \mathrm{C}$.

- Assay tubes (12 ml, round bottom, polypropylene; Greiner Bio-One GmbH, cat. no. 160201).

- Extraction solution I: Methanol/chloroform $/ n$-heptane with a ratio of 10:9:7 (v/v/v) is stored light-protected at $4{ }^{\circ} \mathrm{C}$. Prewarm solution before use.

- Extraction solution II: $0.1 M$ potassium carbonate, $\mathrm{pH} 10.5$ adjusted with saturated boric acid.

- Liquid scintillation cocktail (Roth, Karlsruhe, Germany, cat. no. 0016.3, or equivalent).

- Sonicator Virsonic 475 (Virtis, Gardiner, NJ) or equivalent.

- Liquid scintillation counter (Packard or equivalent).

\subsubsection{Procedure}

2.1.3.1 Preparation of cellular or tissue extracts: Homogenize tissue samples on ice in solution A using an UltraTurrax (IKA, Janke \& Kunkel, Germany) and centrifuge at $1,000 \times g, 4{ }^{\circ} \mathrm{C}$ for $10 \mathrm{~min}$ to remove nondisrupted tissue and nuclei. Thereafter, transfer the 
supernatant to a new tube and centrifuge at $20,000 \times g, 4{ }^{\circ} \mathrm{C}$ for $30 \mathrm{~min}$. Carefully collect the infranatant, leaving the fat layer behind. TG hydrolase activity is determined on the $20,000 \times g$ infranatant. For preparation of cell extracts, harvest cultured cells and disrupt cells in buffer $\mathrm{A}$ by sonication on ice. Thereafter, centrifuge cell lysates at $1,000 \times g, 4{ }^{\circ} \mathrm{C}$ for 10 min to pellet intact cells and nuclei. For cells that do not contain large amounts of TG (e.g., COS-7 cells), the $1,000 \times g$ supernatant is used to measure TG hydrolase activity. Be aware that ATGL, CGI-58, HSL, and MGL may localize on LDs of cells and tissues. Thus, when assaying TG hydrolytic activity of the 20,000 $\times g$ infranatant, a part of the total lipolytic activity might be lost in the fat cake.

2.1.3.2 Measurement of TG hydrolase activity: According to Holm and Østerlund with some modifications (Holm et al., 2001):

1. Add $1.67 \mathrm{~m} M$ TO, $10 \mu \mathrm{Ci}{ }^{3} \mathrm{H}-\mathrm{TO} / \mathrm{ml}$, and $190 \mu M$ PC/PI in an assay tube resistant to organic solvent. For nonadipose tissue samples, a $0.32 \mathrm{~m} M$ TO and $45 \mu M$ PC/PI substrate with same amounts of radiolabel can be used, which will increase the sensitivity of the assay. Bring the solvents to complete dryness under a stream of nitrogen.

2. Add initially not more than $2 \mathrm{ml}$ of $0.1 M \mathrm{KPB}, \mathrm{pH}$ 7.0. Sonicate (Virsonic 475, Virtis, Gardiner, NJ) for $30 \mathrm{~s}$ with an output power of $20 \%$ on ice. Wait for $30 \mathrm{~s}$ and repeat sonication two more times. Be careful that sonicator tip does not touch the walls or the bottom during sonication and avoid foam formation. Ideally, sonicator tip should be on the upper third of the tube.

3. Add remaining KPB as required and sonicate for $15 \mathrm{~s}$ on ice.

4. Add FA-free BSA to give a final concentration of $5 \%$.

5. Measure aliquot of the substrate to determine specific substrate activity (should be around $\left.1 \times 10^{6} \mathrm{cpm} / 100 \mu \mathrm{l}\right)$.

6. Prepare samples on ice. For each determination, use $100 \mu \mathrm{l}$ samples (tissue homogenates or cell lysates) in solution A. As blank, use 100 $\mu$ l solution A. Important: Adapt the amount of protein in the assay experimentally to obtain rates in the linear range of the assay. Prepare at least triplicates for samples and blank. Pipette samples and blanks onto the bottom of assay tubes.

7. Mix $100 \mu \mathrm{l}$ samples with $100 \mu \mathrm{l}$ of substrate by pipetting substrate onto the sample and incubate for $1 \mathrm{~h}$ in a water bath at $37^{\circ} \mathrm{C}$ under constant shaking.

8. Terminate the reaction by the addition of $3.25 \mathrm{ml}$ extraction solution I. Add $1.05 \mathrm{ml}$ extraction solution II and mix vigorously for $5 \mathrm{~s}$ using a vortex.

9. Centrifuge samples at $1,000 \times g$ for $10 \mathrm{~min}$. Transfer $200 \mu \mathrm{l}$ of the upper aqueous phase to a scintillation vial containing $2 \mathrm{ml}$ of scintillation cocktail and analyze radioactivity.

2.1.4 Calculation-Rates of TG/DG/MG or acylglycerol hydrolase activities are presented as amount (nmol) of released FAs per hour and milligram protein. For the 
calculation, the partition coefficient of 1.9 for the extraction of FAs into the water phase (22 ${ }^{\circ} \mathrm{C}$ ), meaning that $71.5 \%$ of FA is recovered into the water phase, is used. Rates are be calculated using the equation as follows:

$$
\frac{(\text { cpm sample }- \text { cpm blank }) \times\left(V_{1} / V_{2}\right)}{(\mathrm{cpm} \text { substrate } / \text { nmol } F A)^{1} \times \mathrm{mg} \text { protein } \times 0.715 \times t}=\mathrm{nmol} \mathrm{FA} / \mathrm{mg} \text { protein } / \mathrm{h}
$$

where $V_{1}$ is the total volume of upper water phase $(2.45 \mathrm{ml}) ; V_{2}$, the volume measured by liquid scintillation $(0.2 \mathrm{ml})$; and $t$, incubation time (h); ${ }^{1} 501 \mathrm{nmol} \mathrm{FA} / 100 \mu \mathrm{l}$ for $1.67 \mathrm{~m} M$ TG substrate; $90 \mathrm{nmol} \mathrm{FA} / 100 \mu \mathrm{l}$ for $0.3 \mathrm{~m} M$ TG substrate; $60 \mathrm{nmol} \mathrm{FA} / 100 \mu \mathrm{l}$ for $0.3 \mathrm{~m} M$ DG substrate; $400 \mathrm{nmol} / 100 \mu \mathrm{l}$ for $4 \mathrm{~m} M \mathrm{MG}$ substrate.

\subsection{Measurement of in vitro DG hydrolase activity}

\subsubsection{Required materials}

- Prepare a $10 \mathrm{mg} / \mathrm{ml}$ DG solution (select isomer as required; Sigma-Aldrich, cat. no. D3627, sn-1,3 DG; cat. no. 42494, sn-1,2 DG; cat. no. D8394, rac-1,2/2,3 DG; cat. no. D8894, $r a c-1,2 / 2,3 / 1,3 \mathrm{DG})$ in chloroform and store at $-20{ }^{\circ} \mathrm{C}$.

- Prepare a $0.5 \mu \mathrm{Ci} / \mu \mathrm{l}$ radiolabeled DG isomer solution (American Radiolabeled Chemicals, Saint Louis, United States, rac-DG [9,10(N)-3H], cat. no. ART0643) in chloroform and store in aliquots of $2 \mathrm{ml}$ at $-20{ }^{\circ} \mathrm{C}$.

\subsubsection{Procedure}

1. Add $0.3 \mathrm{~m} M$ DG, $10 \mu \mathrm{Ci}$ radiolabeled $\mathrm{DG} / \mathrm{ml}$, and $50 \mu M \mathrm{PC} / \mathrm{PI}$ in an assay tube resistant to organic solvents (polypropylene test tubes) and bring to complete dryness under a stream of nitrogen.

2. Further steps are identical as described in steps $2-9$ of Section 2.1.3.2 for measurement of TG hydrolase activity and Section 2.1.4 for calculation of lipase activity.

\subsection{Measurement of in vitro MG hydrolase activity}

\subsubsection{Required materials}

- Prepare a $10 \mathrm{mg} / \mathrm{ml}$ MG solution (select isomer as required; Sigma-Aldrich, cat. no. M7765, 1-oleoyl-rac-glycerol; M2787 2-oleoyl-glycerol) in chloroform and store at $-20{ }^{\circ} \mathrm{C}$.

- Prepare a $0.5 \mu \mathrm{Ci} / \mu \mathrm{l}$ radiolabeled $\mathrm{MG}$ isomer solution (American Radiolabeled Chemicals, e.g., 2-mono oleoyl [9,10-3H(N)] glycerol, cat. no. ART1158) in chloroform and store in aliquots of $2 \mathrm{ml}$ at $-20{ }^{\circ} \mathrm{C}$.

\subsubsection{Procedure}

1. Add $4 \mathrm{~m} M \mathrm{MG}, 2.5 \mu \mathrm{Ci}$ radiolabeled $\mathrm{MG} / \mathrm{ml}$, and $1 \mathrm{~m} M \mathrm{PC} / \mathrm{PI}$ in an assay tube resistant to organic solvents (polypropylene test tubes) and bring to complete dryness under a stream of nitrogen. 
2. Steps $2-9$ are identical as described in Section 2.1.3.2 for measurement of TG hydrolase activity with the modification that the incubation time of the assay is 15 min.

3. For calculation, see Section 2.1.4.

\subsection{Measurement of ATGL-, HSL-, and/or MGL-specific activity using inhibitors}

To determine the TG hydrolase activity of ATGL in tissue samples or cells, HSL activity can be inhibited by specific inhibitors such as NNC0076-0000-0079 (N-methyl-phenyl carbamoyl triazole, Novo Nordisk, Denmark) (Ebdrup, Sørensen, Olsen, \& Jacobsen, 2004; Schweiger et al., 2006) or 4-isopropyl-3-methyl-2-\{1-[3-(S)-methyl-piperidin-1-yl]methanoyl $\}-2 H$-isoxazol-5-1 (BAY; Lowe et al., 2004). Alternatively, murine ATGL can be specifically inhibited by Atglistatin (3-(4'-(Dimethylamino)-[1,1' -biphenyl]-3-yl)-N,Ndimethylurea) (Mayer et al., 2013). To determine MGL-independent MG hydrolase activity, the MGL-specific inhibitor JZL 184 (Cayman Chemicals, Michigan, United States, cat. no. $13158)$ can be used (Long, Nomura, \& Cravatt, 2009). Stock solution $(20 \mathrm{mM})$ of respective inhibitors is prepared in DMSO and stored at $-80{ }^{\circ} \mathrm{C}$. The inhibitors will be added to the samples prior to the addition of substrate. Full inhibition of ATGL, HSL, and MGL activity is obtained at $50 \mu M, 10 \mu M$, and $100 \mathrm{n} M$, respectively. Rates obtained in the presence of inhibitors as compared to that in the absence will give a good approximation for ATGL and HSL activity, respectively.

\subsection{Measurement of LD-associated lipolysis of cultured cells and tissues}

For the analysis of LD-associated lipolytic capacity, LDs of either cultured cells or tissues can be used. The advantage of using LDs from cultured cells is that cells can be transfected with a gene of interest, whose function on LDs can then be analyzed. Furthermore, the TG moiety of cellular LDs can also be radiolabeled, which enhances sensitivity and accuracy of the assay. To investigate lipolytic activity of tissues (e.g., from genetically modified animals, fed/fasted animals, or animals on specific diets), LDs can also be isolated from tissue samples and used as substrate for "self-digestion" experiments.

\subsubsection{Isolation of LDs from cultured cells and tissues}

\subsubsection{Required materials}

- Prepare $4 \mathrm{~m} M$ oleic acid (OA) complexed to $1.35 \mathrm{~m} M$ BSA by the dropwise addition of prewarmed $\left(37^{\circ} \mathrm{C}\right) \mathrm{OA}(8 \mathrm{~m} M$ in water) to prewarmed BSA (FA-free, $2.7 \mathrm{~m} M$ in Dulbecco-PBS, DPBS) under shaking conditions.

- Prepare ${ }^{3} \mathrm{H}-9,10-\mathrm{OA}$ complexed to BSA $(1 \mu \mathrm{Ci} / \mu \mathrm{l} ; 1.4 \mathrm{Ci} / \mathrm{mmol})$ by dissolving $1,000 \mu \mathrm{Ci}{ }^{3} \mathrm{H}-9,10-\mathrm{OA}(5 \mu \mathrm{Ci} / \mu \mathrm{l}$; cat. no. ART 0198, American Radiolabeled Chemicals) in $50 \mu \mathrm{l} 20 \mathrm{mM} \mathrm{NaOH}$ for $15 \mathrm{~min}$ at $37^{\circ} \mathrm{C}$ under shaking conditions. Thereafter, add $950 \mu \mathrm{l}$ of $1 \%$ BSA (in water) and incubate for 5 min while shaking. Ideally, this solution has $1 \times 10^{6} \mathrm{cpm} / \mu \mathrm{l}$ as determined by liquid scintillation counting.

- DPBS. 
- Solution A: $0.25 M$ sucrose, $1 \mathrm{~m} M$ EDTA, $1 \mathrm{~m} M$ DTT, $\mathrm{pH}$ 7.0, $1 \mu \mathrm{g} / \mathrm{ml}$ pepstatin, 2 $\mu \mathrm{g} / \mathrm{ml}$ antipain, and $20 \mu \mathrm{g} / \mathrm{ml}$ leupeptin as Pi's.

- Overlay buffer: $50 \mathrm{~m} M$ KPB (pH 7.4), $100 \mathrm{~m} M \mathrm{KCl}, 1 \mathrm{~m} M$ EDTA, $1 \mu \mathrm{g} / \mathrm{ml}$ pepstatin, $2 \mu \mathrm{g} / \mathrm{ml}$ antipain, and $20 \mu \mathrm{g} / \mathrm{ml}$ leupeptin as Pi's.

- Siliconizing Fluid (AquaSil; cat. no. TS-42799, Thermo Fisher Scientific, Rockford, United States).

- Swing out rotor (SW 41, Beckman or equivalent), corresponding tubes (Herolab or equivalent), and ultracentrifuge (Beckman or equivalent).

- TG reagent (cat. no. TR 22421, Thermo Fisher Scientific) and glycerol standard solution (cat. no. F6428, Sigma-Aldrich).

- BCA reagent and BSA standard (cat. no. 23227, Thermo Fisher Scientific).

\subsubsection{Procedure:}

(A) To isolate radiolabeled LDs from cultured cells:

1. For labeling of TG stores, seed cells at a density of 50,000 cells $/ \mathrm{cm}^{2}$. Incubate semiconfluent cells for $24 \mathrm{~h}$ in the presence of $0.4 \mathrm{mM}$ OA complexed to BSA, containing $0.75 \mathrm{mCi}{ }^{3} \mathrm{H}-9,10-\mathrm{OA} / \mathrm{mmol}$ as tracer.

2. Intensively wash cells with DPBS, suspend in solution A, and disrupt by sonication. Then, proceed with step 3 later.

(B) To isolate LDs from tissue samples:

1. Excise tissue (white and brown adipose tissue or liver), wash intensively with DPBS, and place on ice. For isolation of LDs, frozen tissue is not recommended.

2. Homogenize tissue in solution A on ice using an UltraTurrax (IKA, Janke \& Kunkel, Germany) and centrifuge at $1,000 \times g, 4{ }^{\circ} \mathrm{C}$ for $10 \mathrm{~min}$ to remove nondisrupted tissue and nuclei.

3. Transfer cell/tissue lysates to siliconized tubes, overlay with overlay buffer, and centrifuge $2 \mathrm{~h}, 100,000 \times g, 4{ }^{\circ} \mathrm{C}$.

4. Collect floated LDs from the top of the tubes and resuspend in overlay buffer by brief sonication.

5. Determine the TG content of LDs using TG reagent.

6. Perform protein determination using BCA reagent. As lipids interfere with protein measurement, incubate $20 \mu \mathrm{l}$ of the LD fraction with $200 \mu \mathrm{l}$ BCA reagent. Then, add $0.5 \%$ Triton X-100, mix, and incubate for $10 \mathrm{~min}$ at RT. After centrifugation at $20,000 \times g$ for $10 \mathrm{~min}$, read the absorbance of the underlying solution at $562 \mathrm{~nm}$ (typically the protein content of LDs is $0.5 \mathrm{mg}$ protein/mmol TG). 


\subsubsection{Measurement of lipolysis of isolated LDs from cultured cells}

\subsubsection{Required materials}

- Isolated radiolabeled LDs.

- $\quad 0.1 M \mathrm{KPB}(\mathrm{pH} 7.0)$.

- $\quad$ Pi (1,000×stock): $1 \mathrm{mg} / \mathrm{ml}$ pepstatin, $2 \mathrm{mg} / \mathrm{ml}$ antipain, and $20 \mathrm{mg} / \mathrm{ml}$ leupeptin.

- $\quad 20 \%$ FA-free BSA (Sigma-Aldrich) dissolved in $0.1 M \mathrm{KPB}(\mathrm{pH} 7.0)$.

- Extraction solution I: Methanol/chloroform/n-heptane with a ratio of 10:9:7 (v/v/v) is stored light-protected at $4{ }^{\circ} \mathrm{C}$. Prewarm solution before use.

- Extraction solution II: $0.1 \mathrm{M}$ potassium carbonate, $0.1 \mathrm{M}$ boric acid, $\mathrm{pH}$ 10.5.

- $\quad$ Liquid scintillation cocktail (Roth or equivalent).

- $\quad$ Liquid scintillation counter (Packard or equivalent).

\subsubsection{Procedure}

1. Prepare samples on ice. For each determination, prepare $100 \mu$ sample $(\sim 0.2 \mathrm{mM}$ TG from isolated radiolabeled LD; see 2.5.1). As blank, use $100 \mu$ overlay buffer. Pipette samples and blanks directly onto the bottom of the assay tubes.

2. Add $100 \mu \mathrm{l}$ of $0.1 \mathrm{M} \mathrm{KPB}$, containing $1 \times \mathrm{Pi}$ and $1 \% \mathrm{BSA}$ (FA-free) to samples and blank to give a final volume of $200 \mu \mathrm{l}$. To study the effect of recombinant proteins (e.g. lipases or LD proteins) on hydrolysis of LDs, add purified enzymes or cell lysates containing proteins of interest.

3. Incubate samples and blanks for $1 \mathrm{~h}$ at $37^{\circ} \mathrm{C}$ in a water bath under constant shaking.

4. Terminate the reaction by the addition of $3.25 \mathrm{ml}$ extraction solution $\mathrm{I}$. Add $1.05 \mathrm{ml}$ of extraction solution II and mix vigorously for $5 \mathrm{~s}$ using a vortex.

5. Centrifuge samples at $1,000 \times g$ for $10 \mathrm{~min}$. Then, transfer $200 \mu \mathrm{l}$ of the upper aqueous phase to a scintillation vial containing $2 \mathrm{ml}$ of scintillation cocktail and analyze radioactivity.

2.5.2.3 Calculation: LD-associated lipolytic activity is calculated as the amount of released FA (nmol) per TG $(\mu \mathrm{mol})$ or per protein $(\mathrm{mg})$ amount of the LD and per hour. The partition coefficient for FAs into the water phase is $1.9\left(22^{\circ} \mathrm{C}\right)$, meaning that $71.5 \%$ of OA is recovered in the water phase. For the calculation, the following equation can be used:

$$
\frac{(\text { cpm sample }- \text { cpm blank }) \times\left(V_{1} / V_{2}\right)}{(\text { cpm substrate } / \text { nmol } F A)^{1} \times \mathrm{mg} \text { protein } \times 0.715 \times t}=\mathrm{nmol} \mathrm{FA} / \mathrm{mg} \text { protein } / \mathrm{h}
$$

where $V_{1}$ is the total volume of the upper water phase $(2.45 \mathrm{ml}) ; V_{2}$, volume measured by liquid scintillation $(0.2 \mathrm{ml})$; and $t$, incubation time (h); ${ }^{1} 60 \mathrm{nmol} \mathrm{FA} / 100 \mu \mathrm{l}$ for $0.2 \mathrm{mM} \mathrm{TG}$ substrate. 


\subsubsection{Lipolysis of isolated tissue LDs}

\subsubsection{Required materials}

- Isolated LDs.

- $\quad 0.1 M \mathrm{KPB}(\mathrm{pH} 7.0)$.

- $\quad \mathrm{Pi}(1,000 \times$ stock): $1 \mathrm{mg} / \mathrm{ml}$ pepstatin, $2 \mathrm{mg} / \mathrm{ml}$ antipain, and $20 \mathrm{mg} / \mathrm{ml}$ leupeptin.

- $20 \%$ BSA (FA-free; Sigma-Aldrich) in $0.1 M \mathrm{KPB}$ (pH 7.0).

- $\quad$ NEFA kit and standard solution (cat. no. 999-34691; 995-3479; 991-34891; 993-35191; 276-76491, Wako Chemicals, Neuss, Germany).

- $\quad 10 \%$ Triton X-100.

\subsubsection{Procedure}

1. Incubate $1 \mathrm{~m} M$ TG of isolated LDs with $1 \%$ BSA in $0.1 M \mathrm{KPB}$ containing $1 \times \mathrm{Pi}$ in a final volume of $200 \mu \mathrm{l}$ for $1 \mathrm{~h}$ at $37^{\circ} \mathrm{C}$ in a water bath under constant shaking. In order to evaluate the capacity of ATGL or HSL to hydrolyze natural LDs, add purified enzymes or cell lysates over-expressing the enzyme of interest.

2. Solubilize LDs by the addition of $20 \mu 110 \%$ Triton X-100 (final conc. $1 \%$ ) to the samples, vortex, and incubate for $10 \mathrm{~min}$ at RT.

3. Centrifuge samples for $30 \mathrm{~min}$ at $20,000 \times g$ and carefully transfer the underlying solution, without any lipids in a new tube.

4. 4. Determine FA content in the underlying solution using NEFA kit.

2.5.3.3 Calculation: To calculate net FA release of the tissue LDs, FA levels are also measured from the LD substrate prior to incubation (blank). After subtraction of the blank, lipolysis of tissue LDs is calculated as nmol FA per TG $(\mu \mathrm{mol})$ or per protein $(\mathrm{mg})$ amount of the LDs.

\subsection{Measurement of lipolysis in cultured adipocytes and organ explants}

The most direct assessment of lipolysis is the measurement of the lipolytic products, released by adipocytes or fat explants. This method is based on the measurement of the lipolytic products, FAs, and glycerol in the incubation media. Two lipolytic states can be differentiated, the so-called basal and $\beta$-adrenergic-stimulated states. Stimulation of lipolysis leads to a rapid increase in FA and glycerol release within $15 \mathrm{~min}$, with a quasi linear rate during the first hours which levels off thereafter (see Fig. 10.6). Since the rate of stimulated lipolysis is highest and nearly linear between the first and second hour of $\beta$-adrenergic stimulation, the measurement of the stimulated state requires a preincubation period. Usually, cells or fat explants are preincubated for $1 \mathrm{~h}$ with isoproterenol or forskolin; then, the incubation media is replaced and the released FAs and glycerol of the forthcoming $1 \mathrm{~h}$ period are determined. 


\subsubsection{Measurement of basal and stimulated lipolysis in cultured adipocytes}

\subsubsection{Required material}

- Differentiated adipocytes in 12-well or 24-well plates.

- Dulbecco's modified Eagle's medium (DMEM, 1 g/l glucose; GIBCO, Life Technologies, Carlsbad, CA).

- $\quad 20 \%$ BSA (FA-free) stock solution in PBS (Sigma-Aldrich), sterile.

- DPBS, sterile.

- $\quad$ NEFA kit and standard solution (cat. no. 999-34691; 995-3479; 991-34891; 993-35191; 276-76491,Wako Chemicals, Neuss, Germany)

- Free glycerol reagent and glycerol standard solution (cat. no. F6428; SigmaAldrich).

- Extraction solution: Chloroform/methanol(2:1, v/v), $1 \%$ glacial acetic acid.

- Lysis solution: $\mathrm{NaOH} / \mathrm{SDS}(0.3 \mathrm{~N} / 0.1 \%)$.

- BCA reagent and BSA standard (cat. no. 23227, Thermo Fisher Scientific).

- Forskolin or isoproterenol, $10 \mathrm{~m} M$ stock solutions in DMSO, stored in aliquots at $-20{ }^{\circ} \mathrm{C}$ (Sigma-Aldrich).

- Triacsin C, $5 \mathrm{~m} M$ stock solution in DMSO, stored in aliquots at $-20^{\circ} \mathrm{C}$ (Triacsin $\mathrm{C}$ from Streptomyces sp.; cat. no. T4540, Sigma-Aldrich).

\subsubsection{Procedure}

1. For measurement of stimulated lipolysis, preincubate differentiated adipocytes (i.e., 3T3-L1) in DMEM, containing 2\% BSA (FA-free) and forskolin or isoproterenol in the presence or absence of $5 \mu M$ triacsin $\mathrm{C}$ for $60 \mathrm{~min}$ at $37{ }^{\circ} \mathrm{C}, 5 \% \mathrm{CO}_{2}$, and $95 \%$ humidified atmosphere. For measurement of basal lipolysis, preincubation is not required.

2. Replace the medium by an identical fresh medium containing $2 \%$ FA-free BSA and incubate for $1 \mathrm{~h}$ (=period of measurement). Save media for measurements.

3. Wash cells $2 \times$ with DPBS.

4. Lyse cells with lysis solution (200-500 $\mu \mathrm{l} / \mathrm{well})$ by shaking the plates for $3 \mathrm{~h}$ at room temperature.

5. Determine protein content of the cell lysate using BCA reagent and BSA as standard.

6. Determine free FA and glycerol content of the medium using NEFA kit and free glycerol reagent and the appropriate standard solutions, respectively.

2.6.1.3 Calculation: Lipolysis of adipocytes is calculated as nmol FA and/or nmol glycerol per mg cell protein and hour. 
2.6.1.4 Limitations: To avoid reesterification of FA and glycerol, it is recommended to incubate cells in the presence of $5 \mu M$ triacsin $C$ to inhibit acyl-CoA synthetases. At high lipolytic rates, the capacity of BSA (FA-free) as FA acceptor may become limiting after prolonged incubation time (Fig. 10.6). This will lead to decreased apparent FA release rate and increased reesterification (Paar et al., 2012).

\subsubsection{Measurement of basal and stimulated lipolysis of WAT organ explants}

\subsubsection{Required materials}

- Dulbecco's modified Eagle's medium (DMEM, 1 g/l glucose; GIBCO, Life Technologies, Carlsbad, CA).

- DPBS, sterile.

- Forceps and scissors for organ explant preparations.

- $20 \%$ BSA (FA-free; Sigma-Aldrich) stock solution in PBS, sterile.

- 96-well plates, sterile.

- NEFA kit and standard solution (Wako chemicals).

- Free glycerol reagent and glycerol standard solution (Sigma-Aldrich).

- Extraction solution: Chloroform/methanol (2:1, v/v), $1 \%$ glacial acetic acid.

- Lysis solution: $\mathrm{NaOH} / \mathrm{SDS}(0.3 \mathrm{~N} / 0.1 \%)$.

- $\quad$ BCA reagent and BSA standard (Pierce).

- Forskolin or isoproterenol, $10 \mathrm{~m} M$ stock solutions in DMSO, stored in aliquots at $-20{ }^{\circ} \mathrm{C}$ (Sigma-Aldrich).

- Triacsin C, $\times 5 \mathrm{~m} M$ stock solution in DMSO, stored in aliquots at $-20{ }^{\circ} \mathrm{C}$ (SigmaAldrich).

\subsubsection{Procedure}

1. Surgically remove gonadal adipose tissue, wash in DPBS, and incubate in prewarmed $\left(37^{\circ} \mathrm{C}\right)$ DMEM till use (perform measurements the same day).

2. For measurement of stimulated lipolysis, cut tissue pieces $(\sim 20 \mathrm{mg})$ and preincubate them in $200 \mu \mathrm{l}$ DMEM containing $2 \%$ BSA (FA-free) and $10 \mu M$ forskolin/isoproterenol and in the presence or absence of $5 \mu M$ triacsin $\mathrm{C}$ in 96-well plates at $37{ }^{\circ} \mathrm{C}, 5 \% \mathrm{CO}_{2}$, and $95 \%$ humidified atmosphere for $60 \mathrm{~min}$. For measurement of basal lipolysis, pre-incubation is not required.

3. Transfer fat explants into $200 \mu \mathrm{l}$ of identical, fresh medium and incubate for further $60 \mathrm{~min}$ (=period of measurement) at $37{ }^{\circ} \mathrm{C}, 5 \% \mathrm{CO}_{2}$, and $95 \%$ humidified atmosphere. Save incubation media.

4. Transfer fat explants in $1 \mathrm{ml}$ extraction solution and incubate for $60 \mathrm{~min}$ at $37^{\circ} \mathrm{C}$ under vigorous shaking on a thermomixer. 
5. Transfer fat explants in $500 \mu \mathrm{l}$ lysis solution and incubate overnight at $55{ }^{\circ} \mathrm{C}$ under vigorous shaking on a thermomixer.

6. Determine protein content of the fat explant lysates using BCA reagent and BSA as standard.

7. Determine FA and glycerol content of the incubation media using NEFA kit and free glycerol reagent and appropriate standard solutions, respectively.

2.6.2.3 Calculation: Lipolysis of adipose tissue organ cultures is calculated as nmol FA and/or nmol glycerol per $\mathrm{mg} /$ protein and hour.

2.6.2.4 Limitations: To avoid reesterification of FA and glycerol, it is recommended to incubate fat explants in the presence of $5 \mu M$ triacsin $C$ to inhibit acyl-CoA synthetases. At high lipolytic rates, the capacity of BSA (FA-free) as FA acceptor may become limiting after prolonged incubation times. This will lead to decreased apparent FA release rate and increased reesterification (Paar et al., 2012).

\section{CONCLUSION}

During the last decade, the perception of lipolysis has dramatically changed. Research steadily uncovers the complexity of the lipidome, proteome, and interactome, the regulation of the lipolytic process, and its interconnection with other cellular processes such as lipid and energy metabolism. It has now been recognized that the measurement of mRNA or protein expression of key players in lipolysis is often not enough to determine the lipolytic state of cells and tissues. Not a single biochemical estimation but the combination of in vitro, in situ, and in vivo measurements is required to assess lipolytic capacity and the lipolytic state and to unravel the role of lipolysis in energy metabolism, cellular signaling, the maintenance of normophysiology, and the development of pathologies.

\section{Acknowledgments}

This work was supported by the Grants SFB Lipotox and the Wittgenstein Award Z136 (Ru. Ze.), the grants P24294, P18434, and TRP4 (Ro. Zi.), and the Grant P25193 (A. L.), which are funded by the Austrian Science Fund (FWF).

\section{REFERENCES}

Bezaire V, Mairal A, Ribet C, Lefort C, Girousse A, Jocken J, et al. Contribution of adipose triglyceride lipase and hormone-sensitive lipase to lipolysis in hMADS adipocytes. The Journal of Biological Chemistry. 2009; 284:18282-18291. [PubMed: 19433586]

Clifford GM, Londos C, Kraemer FB, Vernon RG, Yeaman SJ. Translocation of hormone-sensitive lipase and perilipin upon lipolytic stimulation of rat adipocytes. The Journal of Biological Chemistry. 2000; 275:5011-5015. [PubMed: 10671541]

Ebdrup S, Sørensen LG, Olsen OH, Jacobsen P. Synthesis and structure-activity relationship for a novel class of potent and selective carbamoyl-triazole based inhibitors of hormone sensitive lipase. Journal of Medicinal Chemistry. 2004; 47:400-410. [PubMed: 14711311]

Egan JJ, Greenberg AS, Chang MK, Wek SA, Moos MCJ, Londos C. Mechanism of hormonestimulated lipolysis in adipocytes: Translocation of hormone-sensitive lipase to the lipid storage droplet. Proceedings of the National Academy of Sciences of the United States of America. 1992; 89:8537-8541. [PubMed: 1528859] 
Granneman JG, Moore HP, Granneman RL, Greenberg AS, Obin MS, Zhu Z. Analysis of lipolytic protein trafficking and interactions in adipocytes. Journal of Biological Chemistry. 2006; 282:57265735. [PubMed: 17189257]

Haemmerle G, Lass A, Zimmermann R, Gorkiewicz G, Meyer C, Rozman J, et al. Defective lipolysis and altered energy metabolism in mice lacking adipose triglyceride lipase. Science. 2006; 312:734737. [PubMed: 16675698]

Holm C, Olivecrona G, Ottosson M. Assays of lipolytic enzymes. Methods in Molecular Biology (Clifton, N.J.). 2001; 155:97-119.

Huijsman E, Van de Par C, Economou C, Van der Poel C, Lynch GS, Schoiswohl G, et al. Adipose triacylglycerol lipase deletion alters whole body energy metabolism and impairs exercise performance in mice. American Journal of Physiology Endocrinology and Metabolism. 2009; 297:E505-E513. [PubMed: 19491295]

Kliewer SA, Sundseth SS, Jones SA, Brown PJ, Wisely GB, Koble CS, et al. Fatty acids and eicosanoids regulate gene expression through direct interactions with peroxisome proliferatoractivated receptors alpha and gamma. Proceedings of the National Academy of Sciences of the United States of America. 1997; 94:4318-4323. [PubMed: 9113987]

Kralisch S, Klein J, Lossner U, Bluher M, Paschke R, Stumvoll M, et al. Isoproterenol, TNFalpha, and insulin downregulate adipose triglyceride lipase in 3T3-L1 adipocytes. Molecular and Cellular Endocrinology. 2005; 240:43-49. [PubMed: 16009485]

Lass A, Zimmermann R, Haemmerle G, Riederer M, Schoiswohl G, Schweiger M, et al. Adipose triglyceride lipase-mediated lipolysis of cellular fat stores is activated by CGI-58 and defective in Chanarin-Dorfman syndrome. Cell Metabolism. 2006; 3:309-319. [PubMed: 16679289]

Long JZ, Nomura DK, Cravatt BF. Characterization of monoacylglycerol lipase inhibition reveals differences in central and peripheral endocannabinoid metabolism. Chemistry \& Biology. 2009; 16:744-753. [PubMed: 19635411]

Lowe DB, Magnuson S, Qi N, Campbell A-M, Cook J, Hong Z, et al. In vitro SAR of (5-(2H)isoxazolonyl) ureas, potent inhibitors of hormone-sensitive lipase. Bioorganic \& Medicinal Chemistry Letters. 2004; 14:3155-3159. [PubMed: 15149665]

Mayer N, Schweiger M, Romauch M, Grabner GF, Eichmann TO, Fuchs E, et al. Development of small molecule inhibitors targeting adipose triglyceride lipase. Nature Chemical Biology. 2013; 9:785-787.

Nielsen TS, Vendelbo MH, Jessen N, Pedersen SB, Jørgensen JO, Lund S, et al. Fasting, but not exercise, increases adipose triglyceride lipase (ATGL) protein and reduces $G(0) / G(1)$ switch gene 2 (G0S2) protein and mRNA content in human adipose tissue. The Journal of Clinical Endocrinology and Metabolism. 2011; 96:E1293-E1297. [PubMed: 21613358]

Paar M, Jüngst C, Steiner N. a. Magnes C, Sinner F, Kolb D, et al. Remodeling of lipid droplets during lipolysis and growth in adipocytes. The Journal of Biological Chemistry. 2012; 287:11164-11173. [PubMed: 22311986]

Schweiger M, Schreiber R, Haemmerle G, Lass A, Fledelius C, Jacobsen P, et al. Adipose triglyceride lipase and hormone-sensitive lipase are the major enzymes in adipose tissue triacylglycerol catabolism. Journal of Biological Chemistry. 2006; 281:40236-40241. [PubMed: 17074755]

Vaughan M, Berger JE, Steinberg D. Hormone-sensitive lipase and monoglyceride lipase activities in adipose tissue. The Journal of Biological Chemistry. 1964; 239:401-409. [PubMed: 14169138]

Yamaguchi T. Crucial role of CGI-58/alpha/beta hydrolase domain-containing protein 5 in lipid metabolism. Biological \& Pharmaceutical Bulletin. 2010; 33:342-345. [PubMed: 20190389]

Yamaguchi T, Osumi T. Chanarin-Dorfman syndrome: Deficiency in CGI-58, a lipid droplet-bound coactivator of lipase. Biochimica et Biophysica Acta. 2009; 1791:519-523. [PubMed: 19061969]

Yang X>, Lu X, Lombes M, Rha GB, Chi YI, Guerin TM, et al. The G(0)/G(1) switch gene 2 regulates adipose lipolysis through association with adipose triglyceride lipase. Cell Metabolism. 2010; 11:194-205. [PubMed: 20197052]

Yang X, Zhang X, Heckmann BL, Lu X, Liu J. Relative contribution of adipose triglyceride lipase and hormone-sensitive lipase to tumor necrosis factor-alpha (TNF-alpha)-induced lipolysis in adipocytes. The Journal of Biological Chemistry. 2011; 286:40477-40485. [PubMed: 21969372] 
Zhang X, Xie X, Heckmann BL, Saarinen AM, Czyzyk TA, Liu J. Target disruption of G0/G1 switch gene 2 enhances adipose lipolysis, alters hepatic energy balance, and alleviates high fat dietinduced liver steatosis. Diabetes. 2014; 63:934-946. [PubMed: 24194501]

Zechner R, Kienesberger PC, Haemmerle G, Zimmermann R, Lass A. Adipose triglyceride lipase and the lipolytic catabolism of cellular fat stores. Journal of Lipid Research. 2009; 50:3-21. [PubMed: 18952573]

Zimmermann R, Strauss JG, Haemmerle G, Schoiswohl G, Birner-Gruenberger R, Riederer M, et al. Fat mobilization in adipose tissue is promoted by adipose triglyceride lipase. Science. 2004; 306:1383-1386. [PubMed: 15550674] 


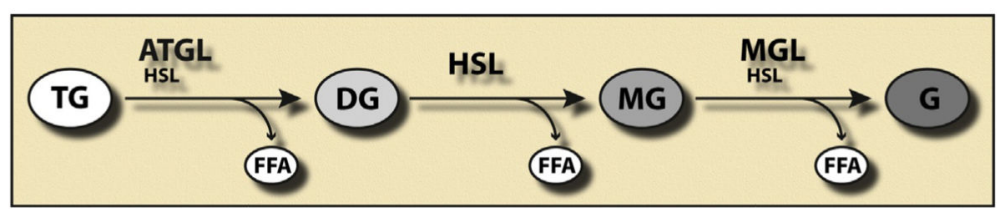

Figure 10.1. Coordinated breakdown of triglycerides in the course of lipolysis. 


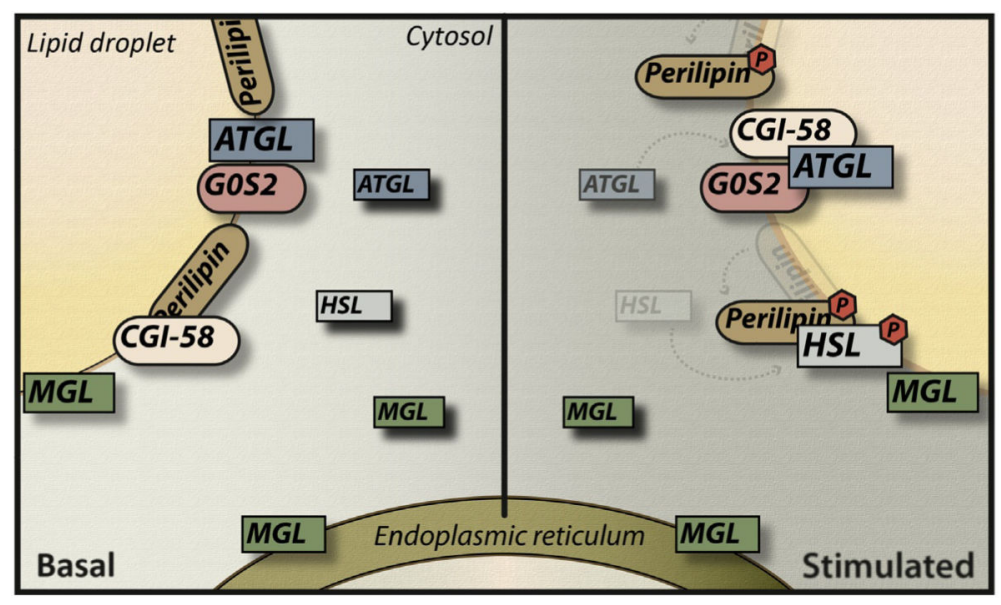

Figure 10.2. Intracellular localization of lipases and regulatory proteins in the basal/nonlipolytic-stimulated state and upon lipolytic stimulation.

In the basal/non-lipolytic-stimulated state, CGI-58 is bound to perilipin-1 and unavailable for ATGL binding/ activation. HSL resides in the cytosol. $\beta$-Adrenergic stimulation leads to the phosphorylation of HSL and perilipin-1, which causes HSL to translocate onto the LD. ATGL also translocates from the cytosol to the LD surface. In both lipolytic states, G0S2 is localized on LD, bound to ATGL. In addition, phosphorylated perilipin-1 releases CGI-58, which is now available for ATGL binding and activation. MGL is localized on the LD, the cytosol, and the ER independent of the metabolic state of the cell. 


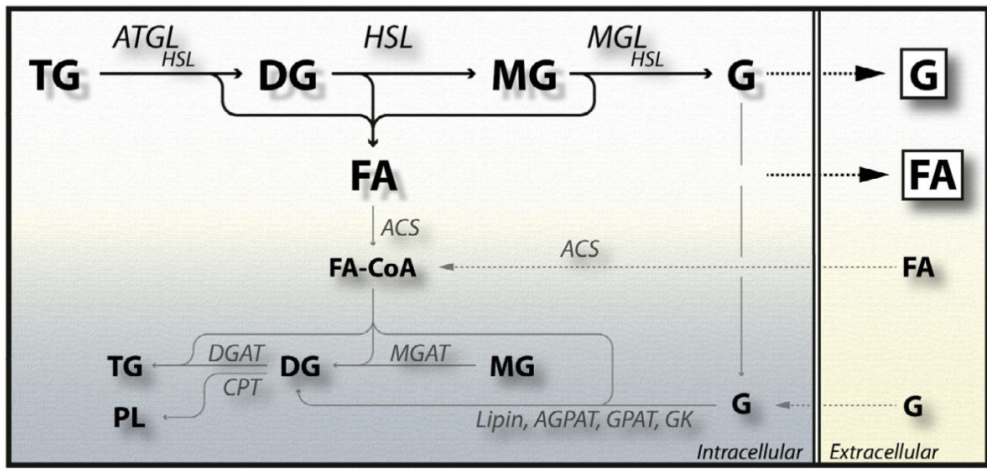

Figure 10.3. The fate of free fatty acids (FA) and glycerol (G) generated during intracellular lipolysis.

FAs generated by the activity of ATGL, HSL, and MGL are either released into the circulation or activated by acyl-CoA synthetases (ACS) to FA-CoA. These FA-CoAs serve as building blocks for the synthesis of MG, DG, TG, and phospholipids (PL), by the activities of MGAT (monoacylglycerol-acyltransferase), DGAT (diacylglycerolacyltransferase), or CPT (cholinephosphotransferase). Glycerol (G) is recycled by GK (glycerol kinase), GPAT (glycerolphosphate-acyltransferase), AGPAT (acylglycerolphosphate-acyltransferase), and lipin to DGs. 


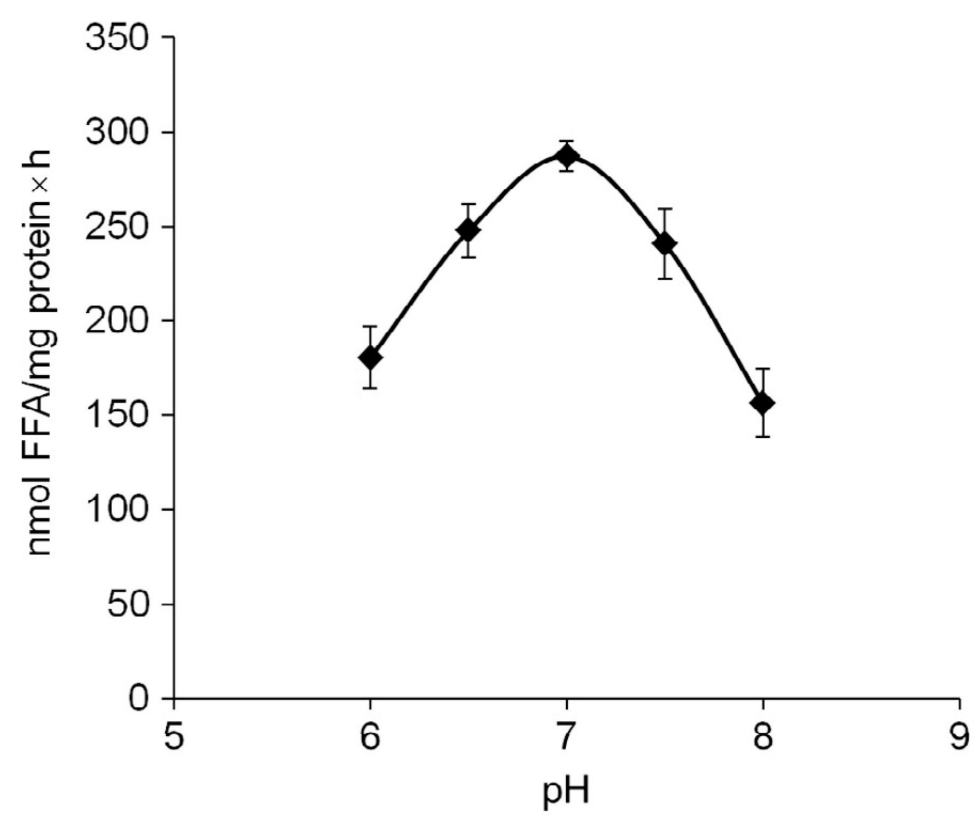

Figure 10.4. pH dependence of CGI-58-coactivated ATGL hydrolysis of TG.

COS-7 cell lysates containing recombinant CGI-58 and ATGL were incubated with 0.32 $\mathrm{m} M$ triolein as substrate and ${ }^{3} \mathrm{H}$-triolein as tracer in $100 \mathrm{~m} M$ potassium phosphate buffer of various $\mathrm{pH}$ (6-8). Substrates were emulsified in phospholipids (PC/PI, 3:1, w/w) containing $5 \%$ BSA (FA-free). After incubation, FAs were extracted and radioactivity was determined by scintillation counting. Data are means \pm standard deviation of three replicates. 

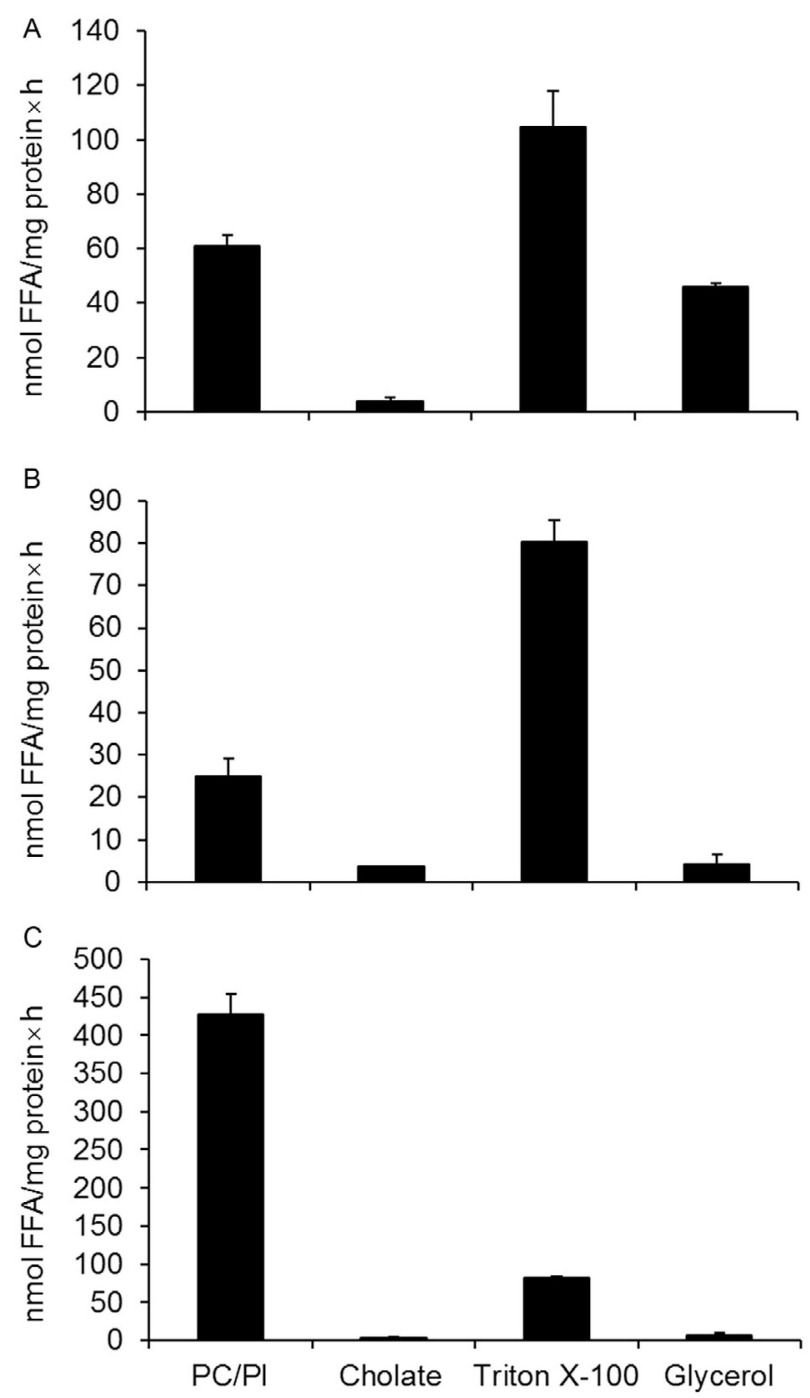

Figure 10.5. TG hydrolase activities of HSL and ATGL using different detergents for substrate preparation.

COS-7 cell lysates containing recombinant HSL (A), ATGL (B), or ATGL and CGI-58 (C) were subjected to TG hydrolase assay using $0.32 \mathrm{~m} M$ triolein as substrate and ${ }^{3} \mathrm{H}$-triolein as tracer. As control, lysates containing recombinant $\beta$-galactosidase (LacZ) were used.

Substrates were prepared in $100 \mathrm{~m} M$ potassium phosphate buffer, $\mathrm{pH} 7.0$, containing $5 \%$ BSA (FA-free). For stabilization $45 \mu M$ PC/PI (3:1, w/w), $20 \mathrm{~m} M$ cholate, $2 \%$ glycerol, or $0.025 \%$ Triton X-100 were used. After incubation, FAs were extracted and radioactivity was determined by scintillation counting. Data are means \pm standard deviation of three replicates. 


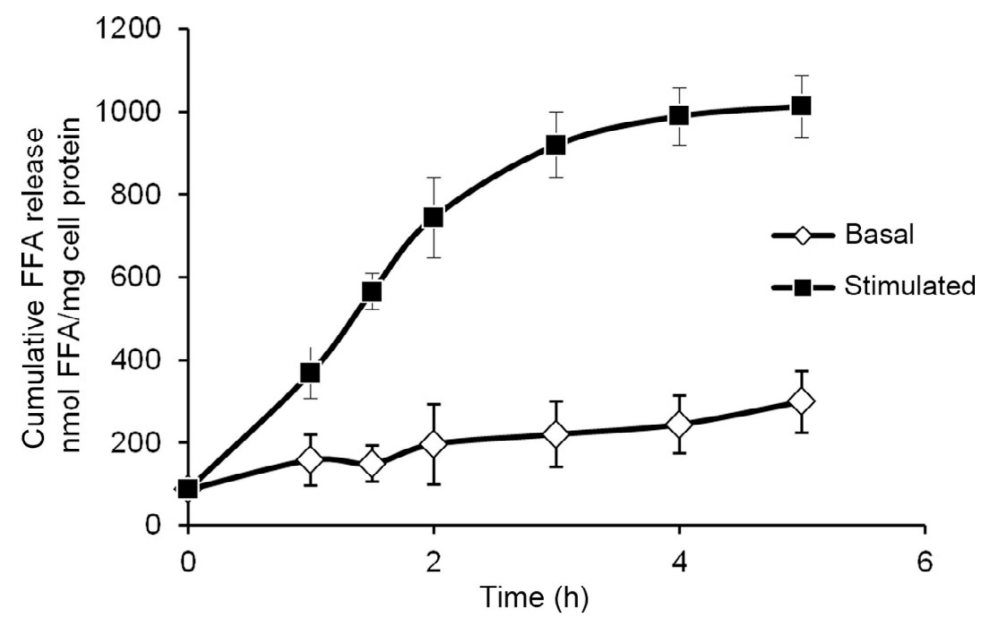

Figure 10.6. Time course of basal and stimulated lipolysis of adipocytes.

Differentiated 3T3-L1 adipocytes were incubated in DMEM containing 2\% BSA (FA-free) in the absence (basal) and presence (stimulated) of isoproterenol $(10 \mu M)$. After various times, the FA content of incubation media was determined and normalized to cellular protein content. Data are means \pm standard deviation of three replicates. 